\title{
Evaluating the Top-Bottom and Bottom-Up Community Development Approaches: Mixed Method Approach as Alternative for Rural Un-Educated Communities in Developing Countries
}

\author{
Alphonsus 0. Isidiho \\ Department of Social and Development Sciences, Faculty of Human Ecology, Universiti Putra Malaysia \\ E-Mail: isidihoalphonsus@yahoo.com \\ Prof. Dr. Mohammad Shatar B. Sabran \\ Department of Social and Development Sciences, Faculty of Human Ecology, Universiti Putra Malaysia \\ E-Mail: shatar@putra.upm.edu.my
}

\section{Doi:10.5901/mjss.2016.v7n4p}

\section{Abstract}

This paper is evaluating the two popular community development approaches; the Top-down and the Bottom-up with their divergent differences in application and the influence each has in developmental projects/ programmes. The authors then proposes a new model / approach "MIXED METHOD". The works of John Cohan and Norman Uphoff, Robert Chambers as earlier advocates of participatory development comes to mind as they tried to deviate from the previous and most popular topdown approach. Considering the fact that there has been arguments on the choice of one against the other, this paper proposes the "mixed method" as the most appropriate approach, as a new approach to balance the dichotomy thereby filling the research gap in search of most appropriate community development method. This advocates the application of both methods as there is need for a mix of both top-down and bottom-up for effective community development. This view of mixed method is borrowed from the supportive and effective empirical evidence for the adoption of mixed methods research in recent time. The review of previous articles, books, conference proceedings, and other internet publications were utilized as the methodological approach hence, the study used secondary data. The paper concludes that there should be a systematic blending or mixing of both top-bottom and bottom-up so as to achieve a holistic and appreciable sustainable development that carries every one along.

Keywords: Evaluation, top-bottom, bottom-top, mixed method, Participation, community Development

\section{Introduction}

The top-down and bottom-up have been used to identify the system adopted in each community developmental projects / programme and researchers have favoured one method or the other depending on their school of thought. Despite each approach, the final analysis of each is the evaluation of the project to know if the goal was achieved and the impact it had on the communities. The strategic objectives of community development include empowering local communities, developing effective partnerships, working as multi-agencies, becoming learning organizations and improving the life and well-being of the rural communities and of course making them sustainable. Be it as it may, community development is embodied in the government's attempt to engage in social engineering in economically disadvantaged communities with a goal of reducing poverty and increasing well-being.

It is important to try to define community so as to set the mind of the reader and also explain development in a brief. Sabran (2003) defined community as "any collectivity of individuals, groups, subgroups and / or institutions or their representations which share time, space and resources for mutual concern". Similarly, Warren, (1972) viewed community as a center for basic functions performed by the community. Which means it is a social system with people living together in relationship with one another who share services and facilities, has a common psychological identity with a common communication network, share the same interest, needs, values and functions. The basic functions were explained as having "both vertical and horizontal interrelationships" (Sabran, 2003, P. 2). In his own view Christenson \& Robinson (1989) says that "Community development is a group of people in a community reaching a decision to initiate a social action process to change their economic, social, cultural and environmental situation". Community from the traditional point of view refers to a group of individuals living or working within the same geographical area with some 
shared cultures or common interests, relies on their collective efforts and may have help from outside. However, the modern understanding of community has seen that the community has gradually developed from the traditional definition where location and boundaries are of major importance to a more advanced community where interest, values and visions are more pronounced.

This brings in a modern definition of Community generally depending on what the group stands for: in terms of locality or territory such as British community or Australian community; as a community of interest or interest group, such as the Black community, Asian Community or White community; and as people sharing a common condition or problem, example community of Heads of States and Governments. Development on its own explains the changes that comes into a place as a result of human activities. And Robert Chambers wrote "development can be taken to mean good change" In this he argues that the change can come from the Elite (Top) or from the "poor, marginalised, vulnerable and excluded". This statement is very significant as it shows that in participation and development, no one knows it best nor has absolute monopoly of knowledge. The poor can also evolve a good idea of positive change when financed, empowered and implemented (Thomas, 2013. P. 2). Huie, (1976), Christenson, \& Robinson (1989) explained that Community Development is the process of making people and their community a better place to live and work by improving their socio-economic and environmental conditions and eradication of poverty. United Nations (1995) stressed that "community development can be tentatively defined as a process designed to create conditions of economic and social progress for the whole community with its active participation and the fullest possible reliance on the community's initiative." This definition has greater emphasis on participatory approach and the people's initiatives in the projects and programmes that would help them to achieve better living, socially, economically and otherwise.

In his own assessment of the definition of community Development (Sabran 2003), stated that the "primary objective of community development is to initiate, structurally direct and sustain the actions of communities for the general wellbeing and such actions and implementations must be backed by the community themselves for effective and positive change", hence he identifies the cores of community development as a process, method, programme and movement. According to Sabran (2003), development implies "improvement, growth and change" and these covers social, psychological, political, economic, sociocultural, environmental and technological transformation in communities and societies. Therefore community development can be seen as a conscious and collective activities of all members of a community to participate in the activities geared towards improving their present wellbeing and that of their future with or without external help. Thomas (2013, P. 1), stated that "Participatory development involves including people who are affected by development processes as planners and implementers and became very popular in the 1980s and 1990s as a response to globalisation and neoliberal development policies". This broadens the participation linkages to mean not only the top (governments and donor agencies) on one hand and the Bottom (rural communities who are the beneficiaries) but also those who may not belong to the two groups but were affected by the developmental processes. This brings in the issue of externalities in economics, as such silent non recognized groups who may not have direct interest in the developments may have to be affected by such development, and therefore participatory in the development under the mixed method approach.

People's desire, interest and comfort in participating in the affairs of their families, work places, and governance have been the source of all agitations in mankind. From the colonial period to the modern era has witnessed lots of agitations and conflicts as a result of oppression, suppressions and neglect in issues that concern them most. The recent agitations in the Arab world named "Arab Spring" can be explained as the quest for people to be actively involved in the issues that concern them most such as governance, social and political involvement and more also liberal democratic society where more people including youths are involved actively in the governance and decision making process of their countries. Whether the "Arab Spring" has achieved its purported objectives or has led to positive changes and improvement or negative and destructive is outside the purview of this study rather the authors are using it to give analogy of the quest for active participation in governance and community development. This political and social agitation is seen as protest against the dominant policies and imposition of policies on the people which is what the top-bottom is talking about and the violent resistance is geared to the request for a bottom-top approach. The fact still remains undoubted that some of the policies has positive impact in the society despite the fact that the communities were not actively involved in the designing and implementation of such policies.

\section{Methodology}

This paper is based on secondary data collected from current literature such as journal papers, conference papers, books and other internet sources. This methodology is used as the topic covered a broad range of countries and developmental approaches hence, no particular standardized data available and distribution of questionnaires to capture the population 
may not be possible.

\section{Literature}

\subsection{Top- Down Method}

According to Popple, (1995), the top-bottom approach is the concern of ruling groups to incorporate and integrate subordinate groups into the dominant ideology in order to ensure their own security and sustainability, and in this psyche they claim to rescue and reform the "deserving" poor, while on the other hand the bottom-up approach, reflects pressure from below or collective community action to better their wellbeing and secure freedom from the dominant class ideology as the communities strive to secure improvement in their life chances and comfort. Therefore, the different approaches varies as one is to continue to maintain dominancy by the people at the "top" over the poor while the other is a struggle by the poor to prove their existence and knowledge of what is good for them. The top-bottom approach is likened to the capitalist and owners of means of production (the bourgeoisie) and the workers or labourers called the proletariats. The Adam Smith's theory of the meat seller who is more interested in the amount the buyer is willing to pay for a piece of meat rather than the quantity of protein or fat derivable from the meat comes into play when talking about the capitalist ideology.

The danger of the top-bottom is that it is a continuous colonialist tendencies of exploiting the resources of the developing countries under the guide that they were helping them to develop. The policies were designed by the colonial masters without taking into cognizance the sociocultural, environmental and political structure of their colonies. Such actions resulted in some resistance from the locals and resulted in wars and dethronement of traditional rulers and chief who resisted such "framed" policies that were not adaptable to their rural communities.

In Nigeria, such issues like the Aba women riot of 1929 and the dethronement and enslavery of prominent chief like king Jaja of Opobo were prominent in history and examples of top-bottom approach in community development. The glaring criticisms of top-bottom approaches is that it starts from the perspectives of central decision-makers and thus tend to neglect other actors. A second, and related, criticism of top-bottom is that it is difficult to use where there is no dominant agency or policy, but rather a multitude of governmental directives and actors, none of them preeminent. And third criticism of top-down models is that they are likely to ignore, or at least underestimate, the strategies used by street level bureaucrats and target groups to get around (central) policy and/or to divert it to their own purposes (Sabatier, 1986, p. 30).

For more scientific and innovative technological developments, top-bottom have proved to be more successful and goal realizable, putting in mind the fact that the local communities may not be exposed to such innovations and technologies. In this situation, a team of experts designs the programmes and try to adopt it to the local communities (Khadka and Vacik, 2011). The top-bottom approach should be organized such that the experts assimilate the locals and integrate them in the programmes so as to have effective impact and the goals of the projects realized, hence collective learning situations established and strengthen the relationship between experts and locals as they shared knowledge and experiences of development. The supporters of the Top-Bottom approach must realize that in this $21^{\text {st }}$ century, it is a cohesion and encroachment into peoples and communities life for things to be imposed on them without their consent as such impositions affects and alters their sociocultural, economic, environmental and political life with displacements and destruction of nature and the ecosystem which by Human Right Declaration should not be infringed upon.

Top-bottom approach means "the starting point is the authoritative decision; as the name implies, centrally located actors are seen as most relevant to producing the desired effects" (Matland, 1995, p. 146). Also, Berman, (1978), had a different view on government and its operation and felt that decision making in governance operates at macro and micro levels. The people implementing such programmes at the local levels makes some adjustments to ensure the successful implementation and realization of the results, such that they form their own opinion and task so as to make the programme adaptable to the rural communities without changing the desired goal. Top-down has nevertheless achieved some marks in developmental projects both in the rural and urban. The business nature, diversity and busy individualistic life in the urban cities has made inter personal relationship non cordial, hence difficult for people to come together to plan development and this has made Top-Down approach the best in the urban cities rather than rural communities.

According to Cooksey \& Kikula (2005, P. 3), Top-Bottom approach being the most common method all over the world is utilized by governments and foreign donor agencies in project implementation and their adaptation of these includes that it "allow rapid, large scale spending of budgets in accordance with pre-established timetables and also gives government planners, donors and the bureaucrats an illusory feeling of control and efficiency". Similarly, Larice \& Macdonald, (2007) said that top-bottom encourages already prepared proposals to be implemented by the authority, 
therefore it's easy to focus at the community consultation process, since the authority predefined the project, and it is not time consuming for the development process as the whole process is controlled by the professional actors without the communities consulted in the implementation. Finally that there is more effective use of resources by using professional expertise to mobilize, co-ordinate and interpret community options.

Augments against top-bottom includes the facts that it has an assumed structured plans and designs, cost and implementation period for projects without considering the variance in the sociocultural and environmental situations in locations. It assumed also the same co-operation from communities where the projects are to be located without considering the variations in culture, living pattern and exposures to new technologies. The approach erroneously assumes also that the communities are naïve and don't know what is good for themselves hence the "top" plans for them and impose such decisions on them. Humans being what we are feels humiliated when actions shows that we are unintelligent and the tendencies are for the communities to disassociate themselves from such projects to prove the "top" wrong and laugh to the failures of such projects. In his own study, Thomas, (2013, P.1), argued, that top-down is being "tokenistic and unable to address the issues of top down development". Cooksey \& Kikula, (2005, P.4) presented that the sources of data in top-bottom surveys are "quantitative data or numerical estimations collected through rapid diagnostic feasibility studies or project formulation missions". Also, "Planners and bureaucrats proceed as if they were writing on a clean slate and possessing all the knowledge for improving people's lives. In reality, they are making interventions in a well-established community social system, which has survived over generations of struggles and interactions with the local environment". The limited participation of other stakeholders in the projects becomes a minus since all the decisions about such projects are centrally planned, adhering to the master plan, having no respect and consideration of environmental changes, local initiatives and development choices (Cooksey \& Kikula, 2005).

The top-bottom approach in community development looks at the developmental strategies of the community from the top and be able to forecast what would the communities be like when such programmes are implemented, and the top here involves the government, donor agencies and other organization. Likewise the investors use Top-down investing approaches and this involves analyzing the "big idea" by looking at the economy and try to forecast which industry will generate the best returns. These investors then look for individual companies within the chosen industry and add the stock to their collections. For example, suppose you believe there will be a drop in interest rate, using the top-down approach, the investor would forecast that the home-building industry would benefit the most from the aggregate and multiplier changes and then limit your search to the top companies in that industry. On the other hand, an investor using a bottom-up overlooks broad scope and economic conditions and focuses on selecting a stock based on the individual attributes of a company. In this case the investor simply seek strong companies with good prospects, regardless of industry or macroeconomic factors, and "good prospects" here is a relative term depending on the views of the individual. Some investors look for earnings growth while others find companies with low but attractive fundamentals with strong and prospective business cycle.

The words of Carey et al (2015. P167) in their definition of top-down approach gives an overview of this approach in contrast to modern community development; "top-down refers to initiatives that are directed from an "authoritative core" at strategic levels of Government". The explanation with the word "authoritative", "emanate" and "flow down" as used by Carey et al (2015) and Keast, (2011) gives a complete insight into the operational system of top-down approach. It is non democratic and hence an enforcement on the people which in this jet age abhors all virtues of human right and democratic freedom. It is a policy decision imposed on the bottom by the authoritative and rulership system of the top who see themselves as "knowing it all".

This is a good explanation of the top- down approach and why the top-down approach is regarded as dogmatic and non-sequential with the developing computer age humanity and technological innovations filled with interdependency, joint research and project implementation in form of corporate integration and sustainability. The joinedup approach adopted by some governments involves the departmentalism and committees in its operation with the aim of involving sub units in programme implementation, "administrative structures such as interdepartmental task forces and intergovernmental committees are common features of joined-up government approaches" (Carey et al (2015, P. 168). Though the joined-up is nice on its own but could not produce nor be compared with the goods of bottom -top as explained in various literature. Combination of the joined-up and the local groups may be able to produce a higher level of results as emphasized in the studies of (O'Flynn et al., 2011; Ross et al., 2011). The negative understanding and effect of the top-down approach by Keast (2011) says "top-down approaches have been found to lack the capacity to reach street-level actions" (Carey et al. 2015, P167). This statement is in agreement with the opposers of top-down who prefer Bottom-up approaches as a better alternative (Cohen \& Uphoff, 1977, Chambers, 1993, Cooksey \& Kikula 2005, Thomas, 2013). 


\subsection{Bottom - Up Method}

A lot of work have been done on bottom - top, otherwise referred as people's participation or democratic process in line with the Millennium Development Goals (MDG) with one main objective and that is to encourage local community and local players to express their views in defining the development course for their area in line with their own views, expectations, plans and their sociocultural life style. It is all known that the new projects and programmes may alter their long existing pattern of life, hence its adoption and implementation has to have a soft landing so as not to disorganize the inhabitants as such impositions would lead to greater resistance and failures of the programmes. Bottom-top community action approach, tends to be locally focused attempts by groups to achieve change in policy and practice and such collective community action consists of relatively small-scale local attempts to negotiate with power holders and initiate projects and programmes they felt would be of great benefit to the communities and enhance their wellbeing. In this case the community tends to be more responsive and active in participation and completion of the projects.

Participation in most cases varies according to the level of participation. It can be passive participation, Quasi or active participation. Passive participation includes just letting people do what you want them to do that has been decided or has already happened and the information belongs only to government, donors or external professionals. There may be quasi participation where certain levels of participation were allowed for the communities such as consultative participation, material incentive participation, forced participation, self-mobilization and functional participation. Finally we have active participation where the community are fully integrated into the project design, planning, implementation and monitoring and evaluation (Cooksey \& Kikula 2005). Participation has continued to metamorphose as modernization comes and one thing that is certain and constant in life is change. Change can be in either directions (positive or negative). In the words of Robert Chambers, "participation has implications for power relations, personal interactions, and attitudes and behaviours and that participatory can apply to almost all social contexts and processes, not least in organisations, education, research, communities and the family" (Thomas, 2013, P. 2).

Bottom -top approach means involving the communities at the various levels of the development programme and covers the definition phase, implementation, evaluation and the revision of the programme either directly or through those bodies representing collective interests such as the professional organisations, women's' groups, cultural associations, etc. Cohen \& Uphoff (1977) and Chambers, (1993) were the early proposals of the theory and framework on participation. While Cohen \& Uphoff (1977) had four dimensions of participation viz: decision making, implementation, benefits sharing and evaluation, Chambers (1993) had stages as project identification, prioritizing, planning, implementation, monitoring and evaluation. Hence the local communities are involved through consultation or by involving them in the partnership which makes them to see the programme as their own and put in all efforts to ensure the successful realization of the goals and sustainability of it too (Isidiho and Sabran, 2015). The bottom-top method involves respecting the ideas and culture of the communities involved, incorporating the needs and visions of the rural people in project execution and respecting their sociocultural diversity coupled with their economic life style and then improve on it for the realization of the goals of the project and its sustainability too. Players in this programme has to be transparent and adaptable to the grass root. A bottom - top approach would entail the experts from the government or foreign organizations trying to dress in the local attires and adjust to their culture for full integration and acceptance from the rural communities. Imagine how the communities would feel seeing a foreigner coming to discuss with them dressed in local fabric and style and speaking also their local dialect.

This first impression gives them the confidence that the foreigner respects their culture and appreciates it too hence they would be highly motivated to working with him and adjusting to the foreign ideas and technologies. This is more proactive system like the assimilation system of government adopted by the French during the colonial period. The bottom-up approach also involves actively involving the few elites in the community and the community leaders in the project design, planning, implementation and evaluation. The problems the few elites pose most times is trying to highjack certain issues in a bid to make personal gains, but a good community developer would know how to get over this by convincing and luring the Elites into full co-operation even if it means assigning some monetary gains to cover their personal cost or putting them on salary. Project selection under the bottom-top involves allowing the communities to choose among list of projects the one that they desire most in line of hierarchy, this is against the top- bottom style of imposing projects on the rural communities by the leaders and governments, ad hoc group of independent experts etc. even when such projects are not the priority of the communities. It is also very important that before any project/ programme is to be implemented in a locality, there is need to identify the various associations and groups existing in such communities and having a pre project discussion with them would help to sensitize the communities on the projects. Such organizations may involve traditional rulers and their cabinet, farmers association, non-farming professionals, other working residents, non-working residents, local political representatives, environmental associations, Cultural 
associations, Women's associations, youth wing etc.

The project stages includes introductory stage which involves planning identification and design, the planning stage, implementation, monitoring and evaluation. All the stages of the projects are important but the question continues to come as to what stages of these projects are the communities to be involved? The stages of involvement depends on the approach adopted, for the Top - bottom approach, the communities may just read or hear that such projects are coming to their locality and they would just wake up one day and see the project officers in their community to start the project. But for the Bottom top, the communities would be consulted in the project identification period and from there to the various other stages ending up with the monitoring and evaluation. The utilization and adoption of bottom-top developmental approach has to start with an organized and enlightened society / community that has certain needs, problems and expectations, that are different from other communities, and can also identify their needs in terms of priority, being also willing to participate in planning, implementation and monitoring to ensure successful completion and benefit sharing. According to Pissourios (2014) the adoption of bottom- top developmental approach may encounter the problem of legislation if the so called development was not covered in the existing central legislation. In this case it means the local communities has to work with the central law makers to enact laws to cover such rurally designed projects to guide against destruction and other illegalities and mitigations that might arise out of the projects. The laws would be able to spell out the does and don't regarding the projects for its completion and sustainability.

Also applicable might be the problems of full participation and control of the projects in larger communities if the bottom- top approach is adopted. This is because it may have to take longer time for the larger communities to assemble. Debate and consensus on certain features, procedures and sharing of the programmes considering the fact that each participating unit would want to have preferential and greater influences in the location and operational modalities of the projects. Such may lead to serious conflict which at the end may lead to distrust, violence, inter and intra personality conflicts. The externalities impact and reflections of some bottom-top projects may become difficult for the communities to internalize hence may be a hindrance to its adoption in some developmental communities. Such big infrastructural projects like roads, water, electricity, airports may need to undergo top-bottom approaches since they involves much technicalities and external supports. Hence the adoption of bottom-top approaches depends on the projects involved and the strength of the local communities and their sponsors. The application of bottom-top approach is not a complete turn around on the top-bottom but a way of making amends and increasing the gains of people's active participation in the affairs of their life and well-being. Thus Participatory approach enables local people to acquire the skills needed to implement and coordinate the management of development projects themselves and thus reap more returns and be able to sustain such goals and gains making it transferrable to generations to come.

\subsection{Mixed Method (Approach)}

The mixed approach in community development is like borrowing a leaf from the mixed methods research. In the words of all advocates of mixed methods in research, it encompasses all the gains of qualitative and qualitative so as to get the best out of the research. . Tashakkori and Teddlie $(1998,2003$,$) sated "A major advantage of mixed methods research is$ that it enables the researcher to simultaneously answer confirmatory and exploratory questions and therefore, generate and verify theory in the same study". Niglas, (1999 and 2004), Hammersley (1992b), Bryman (1988) Creswell (2009), Cresswell \& Plano Clark, (2007), Johnson, Onwuegbuzie, \& Turner, (2007) all argued in favour of mixed methods in getting the best out of modern researches due to the complexity of some research issues. Likewise the mixed approach in community development enables the operators to blend the top-bottom and the bottom- up and such mix realigns and complements each other so as to achieve the goals of community development which involves both the top and the bottom where neither the people at the top nor at the bottom complains. Theoretically this is achievable without much dialogue but practically, it would need the experts to blend the two knowing that naturally there has been long time class consciousness between the rulers and the ruled, the owners of capital and the labour, the policy makers and the local poor. So the application of the mixed method may initially create a class difference and exhibition of supremacy and ego but once the class difference is conquered, implementation of the project would bring a fantastic and co-operative development which would be sustainable and benefiting.

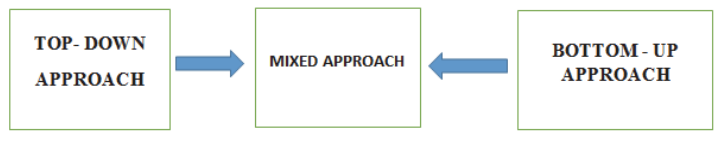

Fig. 1. Mixed Approach

Author's Design of Mixed Approach in Community Development (2016). 
In the mixed method, some silent factors that are prevalent in the life of the rural communities has to be considered by the top and inculcated in the design and implementation process. Most communities have their traits and culture which must be imbedded in the design so as to make them adopt the ideas from the top as they would see the programme as accommodating and then put in their best towards its success. This is in line with the assertions of Arcand \& Wagner (2016, P.122) as they stated that "grassroots-level development projects to be successful, contextual factors need to be integrated into program design and implementation, since they shape local participation". The mix would also encourage serious monitoring of the project and be able to voice out corrupt activities either by the officials from the top or the peasant poor local community members. Hence the mix would serve as check and balances in a world of very high level of corruption among the developing countries. Also another advantage of mixed approach is that some local communities are so poor and uneducated that they cannot fashion out developmental projects/programmes on their own as they lack education and technological innovations. This creates the vacuum of conceptualization, design and implementation of projects by the locals, hence it become more appropriate that the government and international developmental agencies (top) take the responsibility of conceptualizing, designing and implementing the projects but must carry the people along from the start.

There may have to be a pilot study, after which the "top" would know how to involve the locals taking adequate consideration of their socioeconomic, sociocultural, political and environmental situations in the project design. The mixed approach would have the added advantage of eliminating the domination of projects and programmes by the elite who possess stumbling blocks and shields meaningful development from reaching the rural areas and in most cases diverts, misappropriates or embezzles the funds and materials meant for such rural developments. This elite engulfing of projects in rural areas can be checkmated by the top if mixed approach is utilized. There would be room for checks and balances by both the poor and the rich, the donor agencies and government would have opportunity of interactive forum to monitor the implementation of the project and any so called elite manipulating and diverting the resources for the project would be dealt with. Cohen \& Uphoff (1977. P. 63) asked the question of "who" participates. The participants are (1) Local residents (2) Local leaders (informal leaders, association heads and local office holders), (3) Government personnel and (4). Foreign personnel. The question now is at what stage(s) does the mixing come in? To answer this question, the authors suggested starting from the designing stage, to planning, implementation, monitoring and evaluation. Incorporating all these stages in the mixing gives a holistic and goal oriented developmental approach for the rural economy.

\section{Conclusion}

This paper is of the view that both top-down and bottom-top approaches in community development are interwoven as there is no one that is perfect and encompasses developmental projects. There should be a blending or mixing of both to achieve a holistic and appreciable sustainable development that carries every one along. Hence the choice of mixed approach cuts across both top-bottom and bottom- top. The level of awareness in the twenty first century through the social media, open democracy and people oriented incorporation in governance and development calls for full integration of both approaches, making the author's proposed mixed approach stand the test of time as a new development paradigm.

\section{References}

Arcand, Jean-Louis and Natascha Wagner (2016). Does Community-Driven Development Improve Inclusiveness in Peasant Organizations? - Evidence from Senegal. World Development Vol. 78, pp. 105-124.

Berman, P. (1978). The Study of Macro- and Micro- Implementation. Public Policy, pp. 157-184.

Bryman, A. (1988). Quantity and Quality in Social Research. London: Unwin Hyman.

Chamaret, Aurelie, Martin O'Connor, Gilles Recoche (2007). Top-down/bottom-up approach for developing sustainable development indicators for mining: Application to the Arlit uranium mines (Niger). International Journal of Sustainable Development, Inderscience, 10 (1/2), pp.161-174.

Chambers, Robert (1993). Challenging the professions: frontiers for rural development, London: IT Publications.

Carey, Gemma, Brad Crammond, and Therese Riley (2015). Top-Down Approaches to Joined-Up Government: Examining the Unintended Consequences of Weak Implementation. International Journal of Public Administration, 38: 167-178.

Christenson, James A. (1989). Community Development in Perspective. Ames. lowa State University Press.

Cohen, John. M., and Norman T. Uphoff (1977). Rural Development Participation: Concept and Measures for Project Design, Implementation and Evaluation. Rural Development Committee, Cornell University.

Cooksey, Brian and Idris Kikula (2005). When Bottom-Up Meets Top-Down: The Limits Of Local Participation In Local Government Planning In Tanzania. Special Paper No: 17. Research on Poverty Alleviation. Mkuki Na Nyota Publishers. Tanzania. 
Cresswell, J. W. (2009). Research Design: Qualitative, Quantitative, and Mixed Methods Approaches (3rd Ed). Thousand Oaks, CA: Sage.

Cresswell, J. W. \& Plano Clark, V.I. (2007). Designing and conducting mixed methods research, Thousand Oaks, CA Sage.

Dias, Nuwan, Steve Curwell, Erik Bichard (2014). The Current approach of Urban Design and its Implications for Sustainable Urban Development. 4th International Conference on Building Resilience, Building Resilience, 8-10 September 2014, Salford Quays, United kingdom. Procedia Economics and Finance 18, 497 - 504.

Hammersley, M. (1992b). What's wrong with Ethnography? Methodological Explorations. London: Routledge.

Hope, Kempe R. (1980). Social Change and rural regional Community development in the United States. Community Development Journal. 15(2): $110-116$

Huie, J. (1976). What Do We Do About It? - A Challenge to the Community Development Profession. Journal of the Community Development Society. Vol. 6, No. 2: 14-21.

Isidiho A. 0 and Sabran M. S. B. (2015). The role of people's participation, monitoring and evaluation in the successful implementation of Niger Delta Development Commission (NDDC) Projects in Selected Communities in Imo State. Scottish Journal of Arts, Social Sciences and Scientific Studies Vol. 24 Issue 11 pp $125-138$.

Isidiho A. O and Sabran M. S. B. (2015). An evaluation of the effectiveness of leadership in project implementation, governance and community development. Australian International journal of Humanities and Social Studies. Volume 02, Issue 11, Pp. 11 - 22.

Johnson, R. B., Onwuegbuzie, A. J., \& Turner, I. A. (2007). Toward a definition of mixed methods research. Journal of Mixed Methods Research, 1 (2), 112 - 133.

Keast, R. (2011). Joined-up governance in Australia: How the past can inform the future. International Journal of Public Administration, $34(4), 221-231$.

Khadka, Chiranjeewee and Harald Vacik (2011). Comparing a top-down and bottom-up approach in the identification of criteria and indicators for sustainable community forest management in Nepal. Oxford Journals: Forestry. Volume 85, Issue 1, Pp. 145- 158.

Larice, Michael, \& Elizabeth Macdonald. (2007). The urban design reader: Routledge.

Matland, R. E. (1995). Synthesizing the Implementation Literature: The Ambiguity-Conflict Model of Policy Implementation. Journal of Public Administration Research and Theory, pp. 145-174.

Niglas, K. (1999) Quantitative and Qualitative Inquiry in Educational Research: is there a paradigmatic difference between them? Paper given at ECER99; Education Line http://www.leeds.ac.uk/educol/.

Niglas, Katrin (2004). The Combined use of Qualitative and Quantitative Methods in Educational Research. Dissertations submitted to Faculty of Educational Sciences, for the award of Doctor of Philosophy, Tallinn Pedagogical University, Tallinn, Estonia. Short version available at: http://www.ear.ee/e-rmtk/sotsiaalt.htm

O'Flynn, J., Buick, F., Blackman, D., \& Halligan, J. (2011). "You win some, you lose some: Experiments with joined-up government." International Journal of Public Administration, 34, 244-254.

Pissourios, loannis A. (2014). Top-Down and Bottom-Up Urban and Regional Planning: Towards A Framework For The Use of Planning Standards. European Spatial Research and Policy, Volume 21, Number 1, Pp 83 - 99.

Popple, K. (1995). Analysing Community Work: Its Theory and Practice, Milton Keynes: Open University Press.

Popple, Keith and Quinney, Anne (2002). Theory and practice of community development: a case study from the United Kingdom. Journal of the Community Development Society.

Ross, S., Frere, M., Healey, L., \& Humphreys, C. (2011). A whole of government strategy for family violence reform. The Australian Journal of Public Administration, 70(2), 131-142.

Sabatier, P. (1986), 'Top-down and Bottom-up Approaches to Implementation Research: A Critical Analysis and Suggested Synthesis', Journal of Public Policy, 6 (1), pp. 21-48.

Sabran, Mohammad Shatar. (2003). An Introduction to Community Development and Leadership. University Putra Malaysia Press Serdang.

Sanders, I. T. (1970). The Concept of Community Development. Community Development as a Process. University of Missouri, Columbia, Missouri.

Tashakkori, A., \& Teddlie, C., (1998). Mixed Methodology: Combining the Qualitative and Quantitative Approaches, Thousand Oaks, CA: Sage.

Tashakkori, A., \& Teddlie, C., (Eds.). (2003a). Handbook of Mixed Methods in Social and Behavioral Research. Thousand Oaks, CA: Sage.

Thomas Pamela (2013). Challenges for participatory development in contemporary development practice. Development Bulletin No. 75 , August. Development Studies Network. http:crawford.anu.edu.au/rmap/devnet/dev-bulletin.php. (Accessed online March, 2016).

Waren, R. (1978). The Community in America. $3^{\text {rd }}$ Edition. Chicago: Rand McNally.

USAID (1999). Participation at USAID: stories, lessons, and challenges. USAID, Washington, DC.

http://www.africablast.com/2010/12/aba-womens-riot-as-act-of-resistance-of.html

http://www.historians.org/teaching-and-learning/classroom-contenttteaching-and-learning-in-the-digital-age/through-the-lens-of-history-biafranigeria-the-west-and-the-world/the-colonial-and-pre-colonial-eras-in-nigeria/riot-or-rebellion-the-womens-market-rebellion-of-1929

https://en.wikipedia.org/wiki/Women\%27s_War

http://www.revolutionprotestencyclopedia.com/fragr_image/media/IEO_Womens_War_of_1929 